Street, London, S.W.I, on March 16, of a sound apparatus for home use. The device consists of a synchronised turntable attached to the projector by a flexible drive. A special sound disc is used in conjunction with the film, and this is placed on the turntable. An electrical pick-up carries the gramophone needle, which is connected to a loud speaker either by the user's radio set or alternatively by a special amplifier. The makers have prepared a library of films, including comedies and travel and educational films. The device shown worked quite satisfactorily, and the operation of the equipment is simple. In some cases it might be useful in colleges and schools. The turntable is listed at twenty-five guineas, and the hire of a film from the library is $10 s$.

\section{Witchcraft on the Gold Coast}

The Christian Council of the Gold Coast, a body consisting of representatives of all denominations, of which the Anglican Bishop of Accra is chairman, has taken the unusual course-not, however, without precedent in spiritistic circles-of issuing a challenge to witchcraft. The Council has published a notice in the local press that it is prepared to pay the sum of $£ 10$ to any person who, within the term of six months from date, will either 'eat' a papaw, or some other fruit selected by the Committee, at a distance of five yards, without coming into physical contact with it; or extract from a sealed box, without breaking the seal, an article deposited in it by the Committee; or transform himself into any beast, bird, or creeping thing. All these operations are among the powers attributed to the local witches. The Council, in making this challenge, is careful to point out that while many innocent persons are put in great terror by their fear of witcheraft, the harm from it is due not to the powers of witchcraft, but to their fear. Even with this proviso, however, the Council would appear to have been unsuccessful in its attempt to avoid criticism. Objection has been taken to its action on the ground that it constitutes 'witch-finding', and as such is contrary to a local ordinance.

ExTRacts from the local press criticising the Council are quoted in an article describing the situation at Accra, which appeared in the Manchester Guardian of March 15. The Council is recommended to abstain from meddling with witchcraft; and as it does not affirm or deny the belief, it is advised "to leave the Devil alone". Apparently the Council takes its stand on precedent ; for it recalls that in the last hundred years the power of 'fetish priests' has been broken in this manner on many occasions. The action of the Council is directed against 'witch-finders' as well as the witch. Some idea of the conditions with which the churches have to deal may be gained from a case quoted from the Vox Populi, a local journal, of Feb. 20, which reports the 'finding' of a witch, who was. charged with killing the child of a sister. When the dead child was placed on her lap, a snake fell from her body. This was taken as proof positive of her guilt, and the woman had to be conveyed away secretly to save her from popular vengeance.

\section{Prehistoric Society of East Anglia}

AT the annual meeting of the Prehistoric Society of East Anglia, held at Norwich on Feb. 29, Mr. J. Reid Moir was elected president. In a paper on the evolution of the rostrocarinate and hand-axe in north-east Ireland, Mr. J. P. T. Burchell described the geological conditions under which specimens he exhibited were collected. Mr. J. Reid Moir reviewed the typological evidence of the exhibits, showing that the line of evolution from ancestral eolithic forms and the technical methods of flaking used were identical with those in the lower palæolithic industries of widely separated regions. Dr. Muir Evans exhibited a fine bone harpoon from the North Sea bed, deeply peat-stained and similar to the two examples from Holderness now in the British Museum. The specimen came from a large mass of 'moorlog' dredged up between the Leman and Ower sandbanks, about thirty-five miles east of Happisburgh lightship, by the trawler Colinda. Mr. M. C. Burkitt accepted the harpoon as clearly of Maglemose type. The specimen has been presented to the Norwich Museum.

\section{Fungicide for Oat Seed}

ExpERIMENTs carried out at the North of Scotland College of Agriculture, at Craibstone, in 1931, clearly demonstrate the value of dressing oat seed with 'Ceresan', for on an average the yield of grain was $6 \mathrm{cwt}$. and the yield of straw 8 cwt. per acre higher on the treated than on the untreated plots. Ceresan is a mercuric compound in the form of a dry powder, which, when mixed with the seed, kills any fungi that may be adhering to the grain. Thorough mixing is essential if the treatment is to be successful, and special machines are now on the market for the purpose. An old churn, however, has been used at Craibstone with very satisfactory results. Mixing on the floor with a shovel is not recommended, partly on account of the difficulty of obtaining a sufficiently thorough mixing by this means, and partly because of the poisonous nature of the compound and the consequent risk of danger to live stock. Care is therefore needed in handling the powder, and if large quantities are being used, it is advisable for workmen to cover their noses and mouths as a precautionary measure. Five ounces are required for every hundredweight of seed, the cost, exclusive of labour, working out at less than one shilling per acre. Although a good stand of oats, such as was obtained on the plots where the seed had been treated, is eminently desirable, too thick a crop is liable to suffer from lodging, and it seems possible that a saving of seed could be effected if Ceresan treatment were carried out. This and other points of importance, such as the influence of weather conditions at harvest on the effectiveness of the treatment, etc., will be investigated in the experiments which are being continued at Craibstone in the present season.

\section{Submerged Canyon of the Hudson River}

Scrence Service has issued a summary of a recent United States broadcast talk on hydrographic matters, by Lieut.-Comm. R. R. Lukens, of the United States 